\title{
MONITORAMENTO DE DIÓXIDO DE CARBONO EM UM AMBIENTE ESCOLAR
}

\author{
T. T. COMIN $^{1}$ e M. L. AGUIAR ${ }^{1}$ \\ ${ }^{1}$ Universidade Federal de São Carlos, Departamento de Engenharia Química \\ E-mail para contato: tati_comin@yahoo.com.br
}

\begin{abstract}
RESUMO - A qualidade do ar em escolas tornou-se um tema de pesquisa importante nas últimas décadas e monitorar a concentração de dióxido de carbono $\left(\mathrm{CO}_{2}\right)$ é relevante, pois embora seja produto do metabolismo humano, em altas concentrações ocasiona sonolência, redução na produtividade e outros efeitos deletérios. Assim, este trabalho objetivou monitorar as concentrações de $\mathrm{CO}_{2}$ internas (int) e externas (ext) em salas de aula da Escola Dr. Álvaro Guião (situada no centro da cidade de São Carlos - SP), comparando-as com os limites recomendados em normas técnicas e correlacionando-as com a temperatura (T) e a precipitação pluviométrica (PP). Utilizou-se o monitor de gases, modelo MultiRAE IR-PGM54, que possui um sensor de infravermelho não dispersivo, com faixa de detecção de 0 a $5000 \mathrm{ppm}$. Os resultados indicaram que todas as concentrações médias internas foram inferiores a $1000 \mathrm{ppm}$, limite previsto pela ANVISA, e as diferenças entre as concentrações internas e externas foram menores que $700 \mathrm{ppm}$, limite recomendado pela ABRAVA. Os coeficientes de correlação cruzada calculados foram: $\mathrm{PP} \times \mathrm{CO}_{2}$ (int) $=0,39 ; \mathrm{PP} \mathrm{X} \mathrm{CO}_{2}$ (ext) =0,22; $\mathrm{T} \mathrm{X} \mathrm{CO}_{2}$ (int) = -0,16; $\mathrm{T}$ $\mathrm{X} \mathrm{CO}_{2}$ (ext) $=0,66$, que permitiram concluir que a concentração de $\mathrm{CO}_{2}$ tendeu a aumentar em dias chuvosos, de altas temperaturas externas (correlação positiva) e de baixa temperatura interna (correlação negativa), pois neste caso, janelas e portas das salas são mantidas fechadas, impedindo a dispersão do $\mathrm{CO}_{2}$ exalado na respiração.
\end{abstract}

\section{INTRODUÇÃO}

Em ambientes escolares é muito importante o monitoramento de parâmetros ambientais que interferem na qualidade do ar, devido à susceptibilidade de crianças e jovens a potenciais substâncias tóxicas. Além disso, muitas escolas apresentam prédios com manutenção deficitária, fato que somado a deficiência de ventilação e as altas taxas de ocupação, contribuem para a má qualidade do ar interior, comprometendo, além da saúde, o desempenho dos estudantes, conforme apontaram estudos de Mendell e Heath (2005).

Segundo Persily (1996), o nível de dióxido de carbono $\left(\mathrm{CO}_{2}\right)$ em interiores pode ser considerado como um indicador da qualidade do ar, por ser potencialmente prejudicial à saúde dos ocupantes, por sua relação com outros contaminantes internos, por estar relacionado à taxa de ventilação externa, entre outros. Este composto gasoso é originado, principalmente, pela queima de combustíveis fósseis e como produto do metabolismo humano, e a Associação Brasileira de 


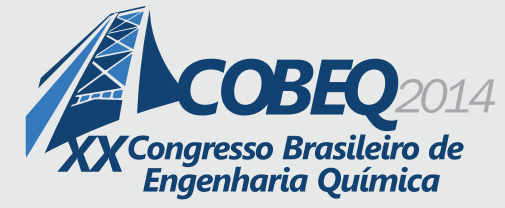

Refrigeração, Ar Condicionado, Ventilação e Aquecimento (ABRAVA) recomenda evitar que a concentração ultrapasse $1500 \mathrm{ppm}$ em ambientes internos ocupados por pessoas sedentárias inativas, pois pode provocar sonolência, redução na produtividade humana, dor de cabeça, aumento na taxa de respiração, além de acelerar os batimentos cardíacos (Mesquita e Araújo, 2006) . Em concentrações na faixa de 30.000 ppm para exposição de 10 minutos, pode causar asfixia por deslocar o oxigênio, logo, recomenda-se que nos ambientes internos seja evitada a saturação do ar por este gás, facilitando a troca de ar com o ambiente externo.

Reconhecida a importância do monitoramento de $\mathrm{CO}_{2}$ em interiores, diante dos fatos supracitados e devido à escassez de trabalhos brasileiros, o objetivo geral deste trabalho foi avaliar as concentrações deste gás na Escola Estadual Dr. Álvaro Guião (situada na região central da cidade de São Carlos - SP), entre os anos de 2010 (de agosto a novembro) e 2011 (de março a junho), com os seguintes objetivos específicos:

- monitorar as concentrações internas em duas salas de aula e no pátio;

- verificar se os níveis amostrados estavam de acordo com os limites previstos em normas técnicas brasileiras;

- calcular o coeficiente de correlação cruzada entre as concentrações obtidas e os níveis de temperatura e de precipitação pluviométrica do período analisado.

\section{LOCAL DE ESTUDO}

A cidade de São Carlos situa-se no centro geográfico do Estado de São Paulo e para este estudo selecionou-se a Escola Estadual Dr. Álvaro Guião, que está localizada entre vias de intenso tráfego urbano, onde aproximadamente 33.000 veículos transitam diariamente. Nesta escola estudam alunos entre 10 e 18 anos de idade, matriculados nas séries dos Ensinos Fundamental II e Médio, e foram selecionadas duas salas de aula para o monitoramento das concentrações de $\mathrm{CO}_{2}$ (denominadas de sala 3 e sala 8), mostradas esquematicamente na Figura 1, e no ano de 2011 o ambiente externo (pátio) também foi monitorado.

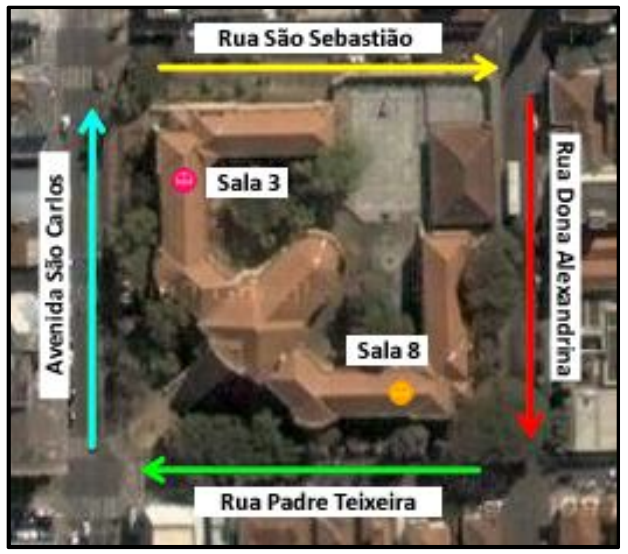

Figura 1 - Esquema da localização da escola e das salas de aula monitoradas. 


\section{METODOLOGIA}

O monitoramento de dióxido de carbono foi realizado com base na Norma Técnica 002 da Resolução no 9 de 2003 (RE 09/2003) da Agência Nacional de Vigilância Sanitária (ANVISA), intitulada "Qualidade do Ar Ambiental Interior. Método de Amostragem e Análise da Concentração de Dióxido de Carbono em Ambientes Interiores", que recomenda a utilização de um equipamento de leitura direta por meio de sensor infravermelho não dispersivo, para uma faixa de concentração de 0 a 5000 ppm.

Cabe ressalvar que a RE 09/2003 da ANVISA, bem como a Resolução Normativa $n^{\circ} 2$ de 2003 (RN 02/2003) da ABRAVA também utilizada para nortear este trabalho, são específicas para ambientes climatizados artificialmente, porém nas salas de aula monitoradas embora existam ventiladores de teto, nem sempre estão ligados, mas não há legislações brasileiras específicas para ambientes de ventilação natural.

Utilizou-se um analisador digital programável de gases, marca RAE Systems, modelo MultiRAE IR - PGM54. Este equipamento realiza sucção de ar e por infravermelho não dispersivo, através de um sensor interno, analisa a concentração de $\mathrm{CO}_{2}$ que é exibida continuamente no visor do equipamento na unidade de ppm (partes por milhão). A luz infravermelha incide através da amostra de gás e a quantidade absorvida pelo $\mathrm{CO}_{2}$ é proporcional à sua concentração. Os dados eram armazenados na memória interna durante cada coleta, cuja duração era de aproximadamente 4 horas, e posteriormente eram descarregados em computador.

Para verificar se a variação nas concentrações de $\mathrm{CO}_{2}$ estava relacionada à variação da temperatura ou do índice de precipitação pluviométrica, decidiu-se efetuar o cálculo do coeficiente de correlação cruzada (ou coeficiente de correlação de Pearson), que permite verificar como duas séries de dados, independentemente medidas, se comportam no decorrer do tempo, ou seja, como elas se relacionam, se o aumento ou redução em uma das séries de dados acompanha a variação da outra. Este coeficiente (representado por " $r$ ") apresenta valores entre -1 e 1, sendo calculado pela Equação 1, onde x e y representam as variáveis correlacionadas, sendo $x_{i}$ e $y_{i}$ os valores individuais e $\bar{x}$ e $\bar{y}$ as médias aritméticas.

$$
r=\frac{\sum_{i=1}^{n}\left(x_{i}-\bar{x}\right) \cdot\left(y_{i}-\bar{y}\right)}{\sqrt{\sum_{i=1}^{n}\left(x_{i}-\bar{x}\right)^{2} \cdot \sum_{i=1}^{n}\left(y_{i}-\bar{y}\right)^{2}}}
$$

Para correlacionar as concentrações de $\mathrm{CO}_{2}$ com a temperatura, foi necessário monitorá-la através de um termohigrômetro digital, marca Rotronic, modelo Hygropalm-0, que permite leitura direta (pontual). Este equipamento opera na faixa de temperatura de $0^{\circ} \mathrm{C}$ a $70^{\circ} \mathrm{C}$ e de umidade de 5\% a 95\%. A correlação com os níveis de precipitação pluviométrica foi possibilitada pelo fornecimento dos dados obtidos pela estação meteorológica situada em São Carlos (SP) da Empresa Brasileira de Pesquisa Agropecuária (EMBRAPA, 2014). 


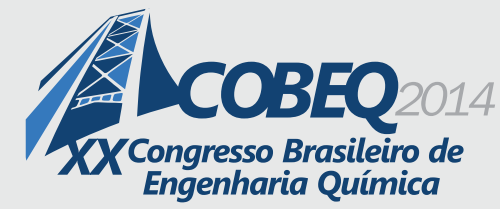

\section{RESULTADOS E DISCUSSÃO}

As médias aritméticas, as medianas e os desvios padrão para os dados de concentração de $\mathrm{CO}_{2}$ das coletas realizadas encontram-se na Tabela 1 . Também é apresentado o índice $\mathrm{I} / \mathrm{E}$ (divisão entre as médias dos valores internos e externos) para as coletas de 2011 cujo monitoramento foi realizado também no exterior das salas de aula.

Tabela 1 - Médias (ppm), medianas (ppm), desvio padrão e índices I/E das concentrações de $\mathrm{CO}_{2}$

\begin{tabular}{cccccccc}
\hline \multirow{2}{*}{ Data } & \multicolumn{5}{c}{ Interna } & \multicolumn{5}{c}{ Externa } & \multirow{2}{*}{ Índice I/E } \\
\cline { 2 - 7 } & Média & Mediana & Desvio & Média & Mediana & Desvio & \\
\hline $23 / 08 / 10$ & 558,9 & 519,0 & 96,6 & - & - & - & - \\
$25 / 08 / 10$ & 502,5 & 504,5 & 51,8 & - & - & - & - \\
$31 / 08 / 10$ & 552,5 & 541,5 & 46,8 & - & - & - & - \\
$02 / 09 / 10$ & 535,1 & 513,0 & 72,0 & - & - & - & - \\
$14 / 09 / 10$ & 505,2 & 495,0 & 38,4 & - & - & - & - \\
$15 / 09 / 10$ & 525,5 & 526,0 & 23,4 & - & - & - & - \\
$20 / 09 / 10$ & 634,0 & 629,0 & 84,5 & - & - & - & - \\
$29 / 09 / 10$ & 789,1 & 716,5 & 181,7 & - & - & - & - \\
$06 / 10 / 10$ & 751,2 & 754,0 & 79,1 & - & - & - & - \\
$07 / 10 / 10$ & 769,0 & 771,0 & 86,6 & - & - & - & - \\
$24 / 11 / 10$ & 706,5 & 701,0 & 41,0 & - & - & - & - \\
$29 / 11 / 10$ & 653,4 & 654,0 & 17,3 & - & - & - & - \\
$30 / 11 / 10$ & 664,7 & 662,0 & 16,5 & - & - & - & - \\
$23 / 03 / 11$ & 881,2 & 871,0 & 52,3 & - & - & - & - \\
$01 / 04 / 11$ & 876,5 & 807,0 & 150,8 & - & - & - & - \\
$14 / 04 / 11$ & 945,3 & 934,0 & 64,6 & 835,1 & 830,0 & 29,9 & 1,13 \\
$27 / 04 / 11$ & 962,7 & 958,5 & 85,0 & 678,2 & 675,0 & 30,0 & 1,42 \\
$05 / 05 / 11$ & 720,9 & 734,0 & 50,3 & 679,8 & 679,0 & 13,3 & 1,06 \\
$09 / 05 / 11$ & 763,9 & 769,0 & 46,3 & 660,8 & 660,0 & 8,2 & 1,16 \\
$25 / 05 / 11$ & 557,8 & 559,5 & 112,9 & 599,9 & 598,0 & 16,2 & 0,93 \\
$31 / 05 / 11$ & 610,7 & 646,0 & 96,9 & 568,0 & 568,0 & 9,3 & 1,08 \\
$02 / 06 / 11$ & 884,8 & 721,0 & 314,1 & 363,4 & 362,0 & 17,8 & 2,43 \\
$06 / 06 / 11$ & 774,3 & 801,5 & 122,4 & 369,5 & 364,0 & 28,3 & 2,10 \\
\hline & & & & & & &
\end{tabular}

A RN 02/2003 da ABRAVA expõe que a concentração média de $\mathrm{CO}_{2}$ no ar exterior normalmente é da ordem de $350 \mathrm{ppm}$, mas pode alcançar $500 \mathrm{ppm}$ em áreas urbanas de tráfego muito intenso de veículos. Observando a Tabela 1 é possível verificar que foram obtidos valores acima de 500 ppm que é um indício da influência do grande fluxo de pessoas e veículos na região da escola, onde inclusive há pontos de ônibus nas ruas ao redor. Pode-se notar também que a maior diferença entre as concentrações interna e externa foi verificada no dia 02/06/11 sendo 
igual à 521,4 ppm, inferior aos 700 ppm recomendado como limite para esta diferença pela ABRAVA e os valores médios internos em nenhum dia ultrapassou os limites propostos pela ANVISA (1000 ppm) e pela ABRAVA (3500 ppm). Porém, durante as amostragens, a concentração de $\mathrm{CO}_{2}$ oscilava muito, então optou-se por construir gráficos do tipo box-plot (ou gráfico de caixas) que estão apresentados nas Figuras 2 e 3 para as salas 3 e 8, respectivamente, nas quais verifica-se alguns picos que superaram o valor de 1000 ppm (limite da ANVISA).

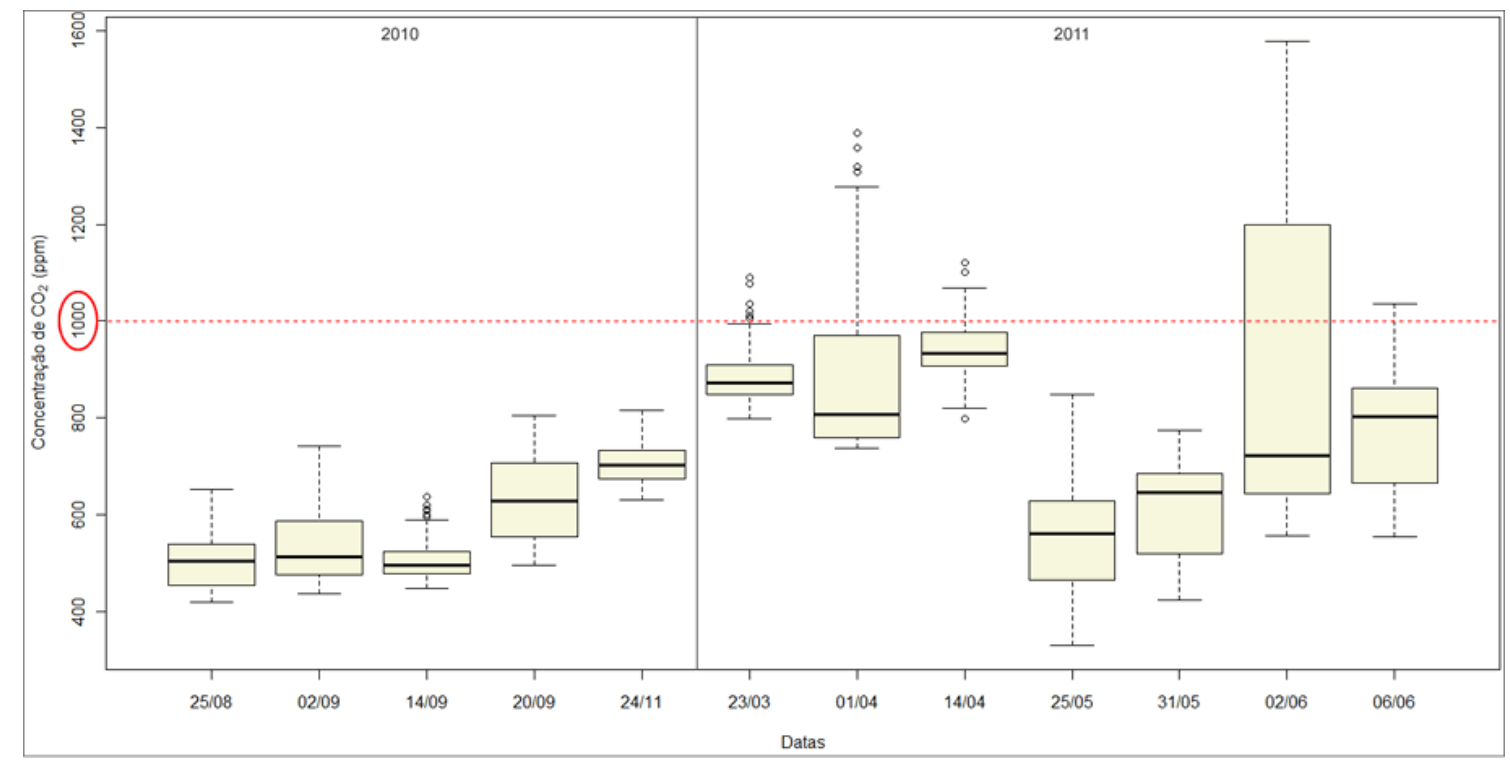

Figura 2 - Concentrações de $\mathrm{CO}_{2}$ amostradas na sala 3.

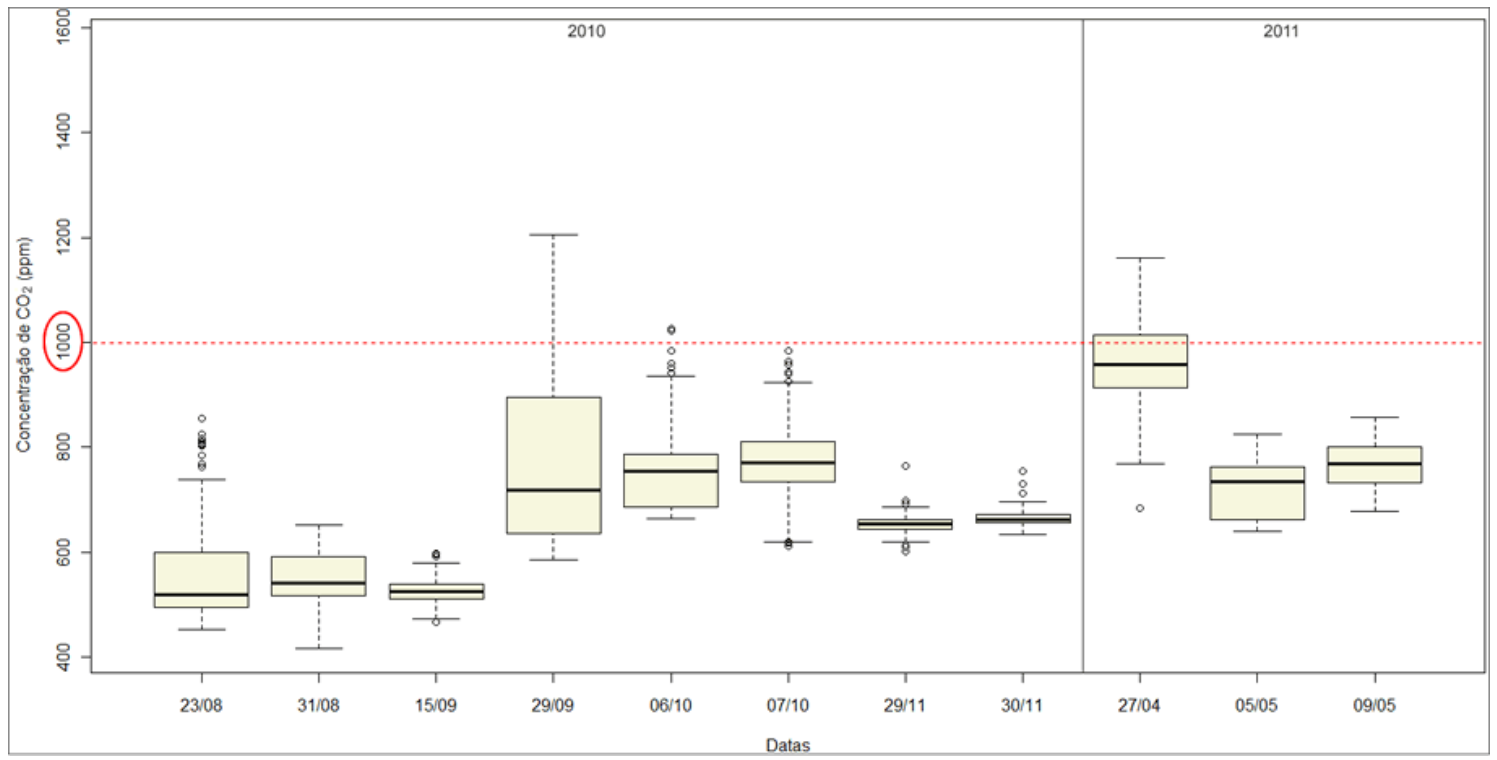

Figura 3 - Concentrações de $\mathrm{CO}_{2}$ amostradas na sala 8 .

Os picos para amostragem interna verificados nos gráficos das Figuras 2 e 3 representam provavelmente a entrada dos alunos após o recreio ou em alguns casos, como no dia 02/06/11, 


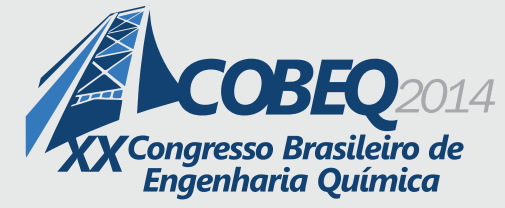

19 a 22 de outubro de 2014

Florianópolis/SC

após a aula de Educação Física. Como as salas permaneciam vazias por minutos, quando os alunos entravam e começavam a exalar dióxido de carbono (produto da respiração humana), as concentrações oscilavam bruscamente.

No ano de 2011 as concentrações externas foram amostradas e encontram-se ilustradas comparativamente com as concentrações internas na Figura 4. Através dela e dos índices I/E maiores que 1 , apresentados na Tabela 1 , foi possível verificar que nas amostragens a concentração interna foi superior à externa, fato que condiz com o que seria esperado, pois ambientes fechados com muitas pessoas tendem a apresentar altos níveis deste gás.

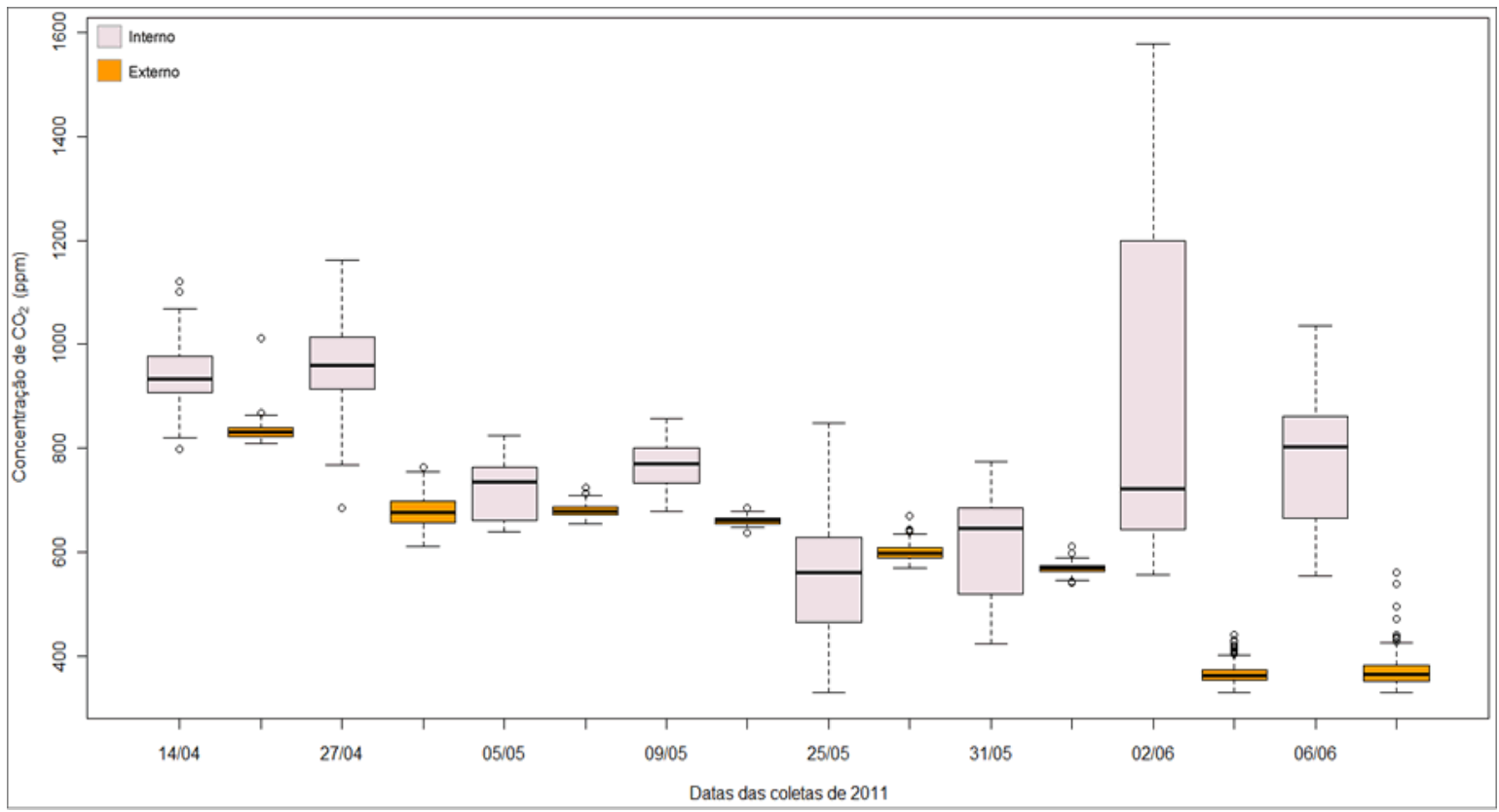

Figura 4 - Comparação das concentrações internas e externas de $\mathrm{CO}_{2}$.

Para verificar a influência da temperatura e dos índices de precipitação pluviométrica nas oscilações verificadas nas concentrações de $\mathrm{CO}_{2}$ obtiveram-se os dados apresentados na Tabela 2.

Tabela 2 - Temperatura média e precipitação pluviométrica nos dias de monitoramento

\begin{tabular}{cccc}
\hline Data & Temp. interna $\left({ }^{\circ} \mathrm{C}\right)$ & Temp. externa $\left({ }^{\circ} \mathrm{C}\right)$ & Prec. Pluv. $(\mathrm{mm})$ \\
\hline $23 / 08 / 10$ & 23,3 & 23,9 & 0 \\
$25 / 08 / 10$ & 24,7 & 24,7 & 0 \\
$31 / 08 / 10$ & 23,9 & 23,3 & 0 \\
$02 / 09 / 10$ & 24,6 & 24,6 & 0 \\
$14 / 09 / 10$ & 29,5 & 29,7 & 0 \\
$15 / 09 / 10$ & 28,4 & 28,6 & 0 \\
$20 / 09 / 10$ & 23,6 & 23,5 & 0 \\
$29 / 09 / 10$ & 21,7 & 21,8 & 0,2 \\
\hline
\end{tabular}


Tabela 2 - Temperatura média e precipitação pluviométrica nos dias de monitoramento (Continuação)

\begin{tabular}{cccc}
\hline Data & Temp. interna $\left({ }^{\circ} \mathrm{C}\right)$ & Temp. externa $\left({ }^{\circ} \mathrm{C}\right)$ & Prec. Pluv. $(\mathrm{mm})$ \\
\hline $06 / 10 / 10$ & 29,9 & 30,0 & 0 \\
$07 / 10 / 10$ & 24,2 & 23,3 & 15,4 \\
$24 / 11 / 10$ & 28,5 & 28,7 & 5,4 \\
$29 / 11 / 10$ & 28,0 & 27,8 & 0 \\
$30 / 11 / 10$ & 25,2 & 25,8 & 1,8 \\
$23 / 03 / 11$ & 23,8 & 23,6 & 0,8 \\
$01 / 04 / 11$ & 25,4 & 25,1 & 0 \\
$14 / 04 / 11$ & 27,7 & 27,2 & 0,2 \\
$27 / 04 / 11$ & 21,2 & 20,9 & 21,2 \\
$05 / 05 / 11$ & 27,4 & 27,0 & 0 \\
$09 / 05 / 11$ & 26,2 & 24,4 & 0 \\
$25 / 05 / 11$ & 22,2 & 22,1 & 0 \\
$31 / 05 / 11$ & 23,4 & 22,9 & 0 \\
$02 / 06 / 11$ & 23,5 & 22,2 & 0 \\
$06 / 06 / 11$ & 23,4 & 21,4 & 0 \\
\hline
\end{tabular}

Os coeficientes de correlação cruzada calculados utilizando os valores de concentrações médias de $\mathrm{CO}_{2}$ disponíveis na Tabela 1 , juntamente com os dados disponíveis na Tabela 2, resultaram em:

$$
\begin{aligned}
& \text { precipitação pluviométrica } \mathrm{X} \mathrm{CO}_{2} \text { (interior) } \rightarrow r=0,39 \\
& \text { precipitação pluviométrica } \mathrm{X} \mathrm{CO}_{2} \text { (exterior) } \rightarrow r=0,22 \\
& \text { temperatura } \mathrm{X} \mathrm{CO}_{2} \text { (interior) } \rightarrow r=-0,16 \\
& \text { temperatura } \mathrm{X} \mathrm{CO}_{2} \text { (exterior) } \rightarrow r=0,66
\end{aligned}
$$

As correlações positivas para os pares de precipitação pluviométrica $\mathrm{x} \mathrm{CO}_{2}$ indicam que a variação de um desses parâmetros causa variação linear no outro, por exemplo, valores altos de precipitação se associam com altas concentrações de $\mathrm{CO}_{2}$ e esta relação é mais forte quanto mais próximo o coeficiente for de +1 . No interior das salas de aula quando chovia, ou seja, quando havia altos valores de precipitação, as janelas e portas eram mantidas fechadas, para evitar que a sala ficasse molhada e para reduzir a interferência do barulho da chuva. Este fato colaborou para aumentar a concentração de $\mathrm{CO}_{2}$ devido a contribuição das emissões humanas, porque a troca de ar entre os ambientes ficou comprometida.

Para os pares de temperatura e $\mathrm{CO}_{2}$, no interior das salas, a correlação foi negativa e no exterior foi positiva. Similarmente, ao que ocorreu quando chovia, quando as temperaturas estavam baixas, ou seja, quando estava frio, as salas de aula eram mantidas fechadas e os alunos exalavam $\mathrm{CO}_{2}$ continuamente contribuindo para aumentar a concentração interna do gás. Desta 


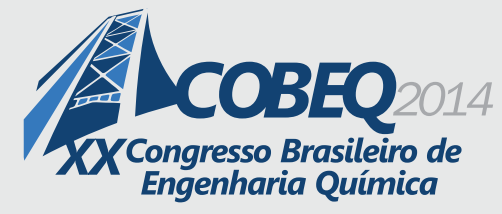

19 a 22 de outubro de 2014

Florianópolis/SC

forma, baixas temperaturas se associaram a altas concentrações e vice-versa. No ambiente externo ocorreu o oposto, porque altas concentrações se inter-relacionam com altas temperaturas, fato este que pode ser associado a estudos como os realizados pelo Painel Intergovernamental de Mudanças Climáticas (IPCC, 2014) que estima que entre 4 e 16 ppm de aumento na concentração de dióxido de carbono atmosférico há o acréscimo de $1{ }^{\circ} \mathrm{C}$ na temperatura.

\section{CONCLUSÕES}

Neste trabalho, todas as concentrações médias de $\mathrm{CO}_{2}$ monitoradas dentro das salas de aula foram inferiores a $1000 \mathrm{ppm}$, respeitando o limite previsto pela RE 09/2003 da ANVISA, e as diferenças entre as concentrações internas e externas foram menores que $700 \mathrm{ppm}$, limite recomendado pela RN 02/2003 da ABRAVA. Quanto as concentrações médias externas, algumas ultrapassaram 500 ppm, que segundo a ABRAVA é um indicador de tráfego muito intenso em áreas urbanas, comprovando a influência do grande fluxo veicular nas concentrações de $\mathrm{CO}_{2}$.

A obtenção de correlação positiva entre concentração de $\mathrm{CO}_{2}$ e precipitação pluviométrica indicou que em dias chuvosos a concentração do gás no ambiente tendeu a ser maior, enquanto a correlação do gás com a temperatura foi negativa para o ambiente interno e positiva para o ambiente externo. Esta diferença pode ser explicada relevando-se que o $\mathrm{CO}_{2}$ é produto do metabolismo humano, assim, em ambientes internos que permanecem com portas e janelas fechadas sua concentração aumenta, o mesmo ocorreu em dias de baixas temperaturas.

\section{REFERÊNCIAS}

AGÊNCIA NACIONAL DE VIGILÂNCIA SANITÁRIA (ANVISA). RE 9: qualidade do ar ambiental interior. Brasília, 2003. 10 p.

ASSOCIAÇÃO BRASILEIRA DE REFRIGERAÇÃO, AR CONDICIONADO, VENTILAÇÃO E AQUECIMENTO (ABRAVA). RN 02: sistemas de condicionamento de ar e ventilação para conforto, qualidade do ar interior. São Paulo, 2003. 18 p.

EMPRESA BRASILEIRA DE PESQUISA AGROPECUÁRIA (EMBRAPA). Dados meteorológicos. Disponível em: <http://www.cppse.embrapa.br/dados-meteorologicos>. Acesso em: 19 mar. 2014.

INTERGOVERNMENTAL PANEL ON CLIMATE CHANGE (IPCC). Properties of $\mathrm{CO}_{2}$ and carbon-based fuel. Disponível em: <http://www.ipcc.ch/pdf/specialreports/srccs/srccs_annex1.pdf>. Acesso em: 25 mar. 2014.

MENDELL, M. J.; HEATH, G. A. Do indoor pollutants and thermal conditions in schools influence student performance? A critical review of the literature. Indoor Air, v. 15, p. 27-52, 2005.

MESQUITA, M. S.; ARAÚJO, F. M. Diagnóstico da qualidade do ar interno das edificações do campus da Unifor. Revista Tecnologia, v. 27, n. 2, p. 163-170, dez. 2006.

PERSILY, A. K. The relationship between indoor air quality and carbon dioxide. Indoor Air, v. 2, p. 961-966, 1996. 